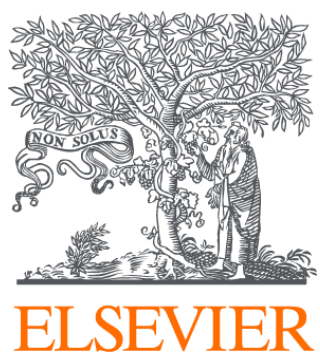

Since January 2020 Elsevier has created a COVID-19 resource centre with free information in English and Mandarin on the novel coronavirus COVID-

19. The COVID-19 resource centre is hosted on Elsevier Connect, the company's public news and information website.

Elsevier hereby grants permission to make all its COVID-19-related research that is available on the COVID-19 resource centre - including this research content - immediately available in PubMed Central and other publicly funded repositories, such as the WHO COVID database with rights for unrestricted research re-use and analyses in any form or by any means with acknowledgement of the original source. These permissions are granted for free by Elsevier for as long as the COVID-19 resource centre remains active. 
Revue générale

\title{
Émergence de virus nouveaux en Asie : les changements climatiques sont-ils en cause?
}

\author{
Emergence of new viruses in Asia: is climate change involved? \\ C. Chastel
}

Laboratoire de virologie, faculté de médecine, 29200 Brest cedex, France

Reçu et accepté le 15 juillet 2004

Disponible sur internet le 17 septembre 2004

\begin{abstract}
Résumé
L'Afrique tropicale n'est pas la seule région du monde où des virus dangereux pour l'homme aient récemment émergé. L'Asie, en particulier la Chine et le Sud-est asiatique, a également connu l'émergence de viroses humaines graves, telles que la dengue hémorragique (les Philippines, 1954) ou plusieurs pandémies grippales, la grippe asiatique (N2H2) en 1957, la grippe de Hong-Kong (H3N2) en 1968, et la grippe russe (H1N1) en 1977. Mais, c'est surtout au cours des dix dernières années que les émergences virales s'y sont multipliées avec l'apparition de la fièvre hémorragique à virus Alkhurma en Arabie Saoudite (1995), de la grippe aviaire H5N1 à Hong-Kong, en 1997, de l'encéphalite à virus Nipah en Malaisie, en 1998, et surtout du SRAS, en Chine du sud en 2002. Les facteurs climatiques n'ont probablement joué qu'un rôle réduit dans le succès émergentiel de ces viroses, favorisé plutôt par des facteurs humains : le développement d'élevages industriels d'animaux de basse cour augmentant les risques d'épizooties, les habitudes alimentaires, les pressions économiques et démographiques, les négligences dans la surveillance épidémiologique et la déclaration des premiers cas.
\end{abstract}

(c) 2004 Elsevier SAS. Tous droits réservés.

\begin{abstract}
Tropical Africa is not the only area where deadly viruses have recently emerged. In South-East Asia severe epidemics of dengue hemorrhagic fever started in 1954 and flu pandemics have originated from China such as the Asian flu (H2N2) in 1957, the Hong-Kong flu (H3N2) in 1968, and the Russian flu (H1N1) in 1977. However, it is especially during the last ten years that very dangerous viruses for mankind have repeatedly developed in Asia, with the occurrence of Alkhurma hemorrhagic fever in Saudi Arabia (1995), avian flu (H5N1) in Hong-Kong (1997), Nipah virus encephalitis in Malaysia (1998,) and, above all, the SARS pandemic fever from Southern China (2002). The evolution of these viral diseases was probably not directly affected by climate change. In fact, their emergential success may be better explained by the development of large industry poultry flocks increasing the risks of epizootics, dietary habits, economic and demographic constraints, and negligence in the surveillance and reporting of the first cases.
\end{abstract}

(C) 2004 Elsevier SAS. Tous droits réservés.

Mots clés : Asie ; Zoonoses ; Émergences virales ; Grippe aviaire H5N1 ; Encéphalite à virus Nipah ; SRAS

Keywords: Asia; Zoonosis; Viral emergence; Avian flu H5N1; Nipah virus encephalitis; SARS

\section{Introduction}

Au cours des cinquante dernières années, la plupart des virus « nouveaux » qui ont émergé provenaient d'Afrique

Adresse e-mail : chastelc@aol.com (C. Chastel). subsaharienne : fièvres hémorragiques africaines (Marburg, Lassa, Ebola), sida, monkeypox, donnant l'impression que le continent africain était le réservoir de virus essentiel de la planète. Mais d'autres virus nouveaux ont également émergé en Asie, dont ceux de plusieurs pandémies grippales, de la dengue hémorragique et, plus récemment, le virus H5N1 de 
Tableau 1

Les principales infections virales humaines identifiées en Asie, en 1930-1940

Main human viral infections identified in Asia between 1930 and 1940

\begin{tabular}{llll}
\hline Maladie & Virus & Vecteurs & Géographie \\
\hline Encéphalite japonaise & flavivirus & Moustiques, en particulier Cx. tritaeniorhynchus & Japon, SE asiatique Chine, Sibérie Inde, Indonésie \\
Encéphalite vernoestivale russe & flavivirus & Ixodes persulcatus et autres tiques & Sibérie, de l'Oural à Vladivostok \\
Fièvre hémorragique de Crimée & nairovirus & Tiques, en particulier des Hyalomma & Sud de l'ex. URSS, Asie Centrale, Pakistan, Inde \\
Fièvre hémorragique de Corée- & hantavirus & Le mulot Apodemus agrarius coreae & Chine, Corée \\
Mandchourie & & &
\end{tabular}

la grippe aviaire, le virus Nipah et le coronavirus du SRAS. Quant aux virus du sida, ils continuent de progresser chaque jour en Asie, notamment dans les pays les plus peuplés, l'Inde, la Chine et l'Indonésie.

Le but de cette revue est non seulement de dresser le bilan des dernières émergences virales sur ce continent, mais aussi d'apprécier la part relative des facteurs humains et des facteurs environnementaux dans l'émergence et la réussite émergentielle [1] de ces virus.

\section{L'histoire virologique de l'Asie est, en fait, très riche}

\subsection{Les années 1930-1940}

Pendant cette période, les techniques virologiques étaient encore sommaires. Elles ont cependant permis l'isolement de certains des tous premiers virus reconnus pathogènes chez l'homme. Ils sont répertoriés dans le Tableau 1. Ce sont tous des agents de zoonoses rurales entraînant chez l'homme une pathologie sévère et une mortalité pouvant dépasser le tiers des malades. Parmi les survivants des encéphalites, les séquelles neurologiques sont fréquentes et graves. Si leur nature virale a été assez rapidement prouvée pour l'encéphalite japonaise (1934), pour l'encéphalite vernoestivale russe (1937) et pour la fièvre hémorragique de Crimée (1945), il a fallu attendre la fin des années 1970 pour que le virus de la fièvre hémorragique de Corée Mandchourie, maladie connue depuis les années 1930 sur les deux rives du fleuve Amour, soit enfin isolé et caractérisé [2].

Il existe un bon vaccin contre l'encéphalite japonaise, le vaccin Biken inactivé, produit sous licence par PasteurMérieux. Il convient pour la protection des personnes vivant ou se déplaçant en zone d'endémie (cf. géographie, Tableau 1), pour leur travail ou leurs loisirs. Pour se protéger éventuellement de l'encéphalite vernoestivale russe, on dispose du vaccin inactivé FSME - Immuno ${ }^{\circledR}$ inject. Il a été mis au point en Autriche contre le virus de l'encéphalite européenne à tiques. Cette dernière virose est transmise par la tique Ixodes ricinus et son agent est un variant ouesteuropéen du virus russe. En France, ces vaccins sont accessibles dans les centres de vaccination contre la fièvre jaune.

\subsection{Les années 1950-1970}

Les progrès de la virologie ont permis de beaucoup améliorer nos connaissances sur les virus asiatiques.
Ainsi, la dengue hémorragique est apparue en 1954 aux Philippines et elle a envahit ensuite tout le Sud-est asiatique [3]. Plus qu'une émergence virale, c'était celle d'une nouvelle forme clinique, plus grave, parfois mortelle, de la « dengue classique » habituellement bénigne [4]. Contrairement aux fièvres hémorragiques précédemment décrites en Asie (cf. 2.1), il s'agissait d'une maladie urbaine, frappant surtout de jeunes enfants autochtones et les vecteurs n'étaient pas des tiques mais des moustiques, Aedes aegypti et Aedes albopictus [4]. Plus tard, de jeunes adultes furent également atteints.

Pour expliquer son apparition, on a invoqué des facteurs essentiellement anthropiques. Le développement monstrueux des grandes métropoles asiatiques, au cours des années 1950-1960, a provoqué la prolifération des vecteurs, surtout d'A. aegypti, en même temps qu'une démographie galopante assurait un volant constamment renouvelé de jeunes enfants réceptifs. La circulation accélérée des quatre types sérologiques du virus de la dengue a provoqué une sensibilisation immunologique séquentielle de ces enfants, par ces flavivirus [5]. Il en est résulté une cascade d'événements immunopathologiques conduisant à la fragilité capillaire, aux hémorragies et au choc hypovolémique, mortel dans 10 à $50 \%$ des cas.

On ne dispose toujours d'aucun vaccin efficace contre la dengue qui est devenue, chez l'enfant, l'un des principaux problèmes de santé publique, en Asie du sud-est.

Par ailleurs, deux autres fièvres hémorragiques virales, de distribution géographique plus restreinte et de moindre importance en santé publique ont été décrites. En 1957, la fièvre de la forêt de Kyasanur a été identifiée en Inde, dans l'état de Karnātaka, et la fièvre hémorragique d'Omsk l'a été en 1959, en Sibérie occidentale. Toutes deux sont transmises par des tiques et leurs agents étiologiques sont des flavivirus [6]. Le tableau clinique, fait d'hémorragies et de troubles neurologiques, est voisin dans les deux maladies et la mortalité ne dépasse pas $5 \%$.

Mais le principal événement virologique fut l'apparition de pandémies grippales $A$ : en 1957, la «grippe asiatique » (H2N2) et en 1968, la " grippe de Hong-Kong » (H3N2). Elles ont permis de dégager une doctrine permettant d'expliquer l'apparition en Chine du sud de virus grippaux entièrement nouveaux, par réassortiment génétique [7]. L'existence dans de nombreuses régions rurales de ce pays, d'élevages de canards et de porcs, en étroite promiscuité avec la population, favorise le phénomène. Le réservoir principal des virus grip- 
paux dans la nature est constitué par des oiseaux aquatiques. Leur infection est habituellement asymptomatique, mais ils excrètent par leur cloaque des quantités considérables de virus, de formules antigéniques très variées. Ces virus peuvent facilement infecter le porc qui est aussi très sensible aux virus grippaux A de l'homme. Cela facilite les infections mixtes du porc et les réassortiments, à l'origine de l'émergence de nouveaux virus. C'était, du moins, le dogme jusqu'à récemment.

\subsection{Les années 1970-1980}

L'Asie a subi, alors, comme le reste du monde, l'impact de plusieurs pandémies virales.

Ainsi, des enterovirus nouveaux ont, en 1969-1973, envahi la planète, provoquant une pathologie jusque là inconnue : la conjonctivite hémorragique épidémique. Cette virose oculaire extrêmement contagieuse provoque du larmoiement, des douleurs oculaires violentes, des hémorragies sous-conjonctivales et, éventuellement, une kératite. Apparue en Afrique occidentale (1969), elle a ensuite gagné rapidement le reste de l'Afrique, l'Europe et l'ensemble de l'Asie, tout particulièrement l'Inde, le Japon et Singapour (1971). Deux virus différents en étaient responsables : un variant du coxsackievirus A24 et l'enterovirus 70 [8]. L'Inde fut à nouveau touché en 1975. Il n'existe ni traitement spécifique, ni vaccin.

Mais la pandémie la plus grave est, sans conteste, celle du sida, reconnu à partir de 1981. Les virus responsables ont été rapidement isolés et caractérisés, le VIH 1 en 1981 et le VIH 2 en 1985. Depuis, la maladie ne cesse de s'étendre dans le monde, l'Asie constituant le deuxième foyer mondial, après celui de l'Afrique subsaharienne. Les pays les plus peuplés de la terre, l'Inde ( 4 millions de personnes infectées) et la Chine ( 840000 infections) sont gravement atteints ainsi que tout le Sud-est asiatique. Fin 2003, la région Asie-Pacifique comptait 7,4 millions de sujets infectés [9].

L'Asie est aussi une terre d'élection des hépatites virales. Les virus A et B y sont largement répandus et c'est à Taiwan que fut confirmé, de façon indiscutable, le lien existant entre l'hépatite B et le cancer primitif du foie [10]. À la fin des années 1980, les progrès de la virologie moléculaire ont montré que les virus $\mathrm{C}$ et $\mathrm{E}$ étaient également très présents en Asie [11,12]. De plus, c'est en Inde que la notion d'extrême gravité de l'hépatite $\mathrm{E}$ chez la femme enceinte (mortalité 20\%) a été établie [13].

Enfin, en 1977, on a observé la réémergence du virus grippal A (H1N1), responsable de la « grippe russe ». Le virus est apparu pratiquement simultanément en Chine et en Sibérie [14].

\section{3. Émergence de virus nouveaux en Asie, au cours des dix dernières années}

Ces émergences se sont produites à un rythme accéléré et certaines ont été particulièrement spectaculaires.

\subsection{La fièvre hémorragique à virus Alkhurma (ALK)}

Elle est provoquée par un flavivirus nouveau qui a émergé en 1995 chez des bouchers d'abattoir, à Djedda, en Arabie Saoudite. Proche du virus de la forêt de Kyasanur (KFD), ALK provoque comme ce dernier une fièvre hémorragique sévère ou, plus rarement, une encéphalite [15]. La source de la contamination est constituée par des moutons. Actuellement, 24 cas ont été identifiés à Djedda et à la Mecque, avec une mortalité de $25 \%$ [16]. Le génome du virus a été entièrement séquencé confirmant ses parentés génétiques avec le virus KFD [16]. Mais les virus KFD et ALK occupent des niches écologiques totalement distinctes : une forêt humide dans le nord de l'Inde, peuplée de singes et infestée de tiques pour KFD ; un environnement semi-désertique pour ALK. Outre le contact avec le sang de moutons infectés, la maladie pourrait être transmise par des tiques ou, encore, par la consommation de lait cru de chamelle. Elle sévit en deux pics annuels : mai-juin et septembre-octobre [16]. Aucun vaccin n'est disponible actuellement.

\subsection{La grippe aviaire H5N1 de Hong-Kong}

Lorsqu'en 1997, l'épidémie de grippe A (H5N1), d'origine aviaire, éclata à Hong-Kong, elle eut immédiatement un fort retentissement médiatique. Ce pouvait être le début, tant redouté, d'une nouvelle pandémie grippale qui, telle celle de 1918-1919, pouvait faire des millions de morts [17,18].

Les choses avaient débuté à bas bruit. En mai 1997, un garçon de trois ans était mort d'une pneumonie grippale compliquée d'un syndrome de Reye. La souche virale isolée à cette occasion était un virus grippal A non caractérisable par les méthodes courantes. C'était en réalité un virus grippal aviaire, de formule antigénique $\mathrm{H} 5 \mathrm{~N} 1$, jamais rencontré chez l'homme [19,20]. Fin 1997, 17 nouveaux cas survinrent à Hong-Kong entraînant cinq autres décès, ce qui portait la mortalité totale à $33 \%$, chiffre jamais atteint dans la grippe humaine. La plupart des malades avaient moins de 15 ans, mais il y avait d'autres sujets nettement plus âgés.

Depuis le printemps 1997, il y avait eu trois épizooties dans des élevages de poulets à Hong-Kong. Elles étaient également dues au virus H5N1 [21] et les souches isolées de la volaille étaient identiques génétiquement à celles des cas humains. Toutes les souches, humaines et animales, étaient d'un type purement aviaire. Stupéfaction ! Un virus grippal A aviaire avait franchi directement la « barrière d'espèce » humaine, sans réassortiment génétique préalable chez le porc. On extermina un million et demi de poulets fin 1997 et l'épidémie s'arrêta.

Il fut démontré que la transmission inter-humaine n'avait joué aucun rôle dans la propagation de l'épidémie, les malades s'étant tous probablement contaminés auprès de poulets infectés. Le virus n'avait pas diffusé plus avant dans la population de Hong-Kong, justement du fait qu'il n'y avait pas eu de réassortiment avec les souches humaines.

Mais pourquoi le virus H5N1 de Hong-Kong avait-il entraîné des infections d'une telle gravité chez l'homme ? 
L'autopsie de deux patients décédés a montré des altérations diffuses, un syndrome hémophagocytaire, de la nécrose des hépatocytes et des tubules rénaux, avec une forte déplétion lymphocytaire. Pendant la maladie, il y avait eu une hyperproduction des cytokines INF- $\gamma$ et Il-6, et du récepteur soluble de Il-2 [22]. Quant aux souches virales elles-mêmes, elles présentaient un site polybasique de clivage de l'hémagglutinine, caractéristique des souches aviaires très virulentes [21]. De plus, les souches provenant de malades induisaient dans des macrophages humains cultivés in vitro, des quantités plus importantes de TNF- $\alpha$ et d'INF- $\beta$ que les souches humaines $\mathrm{H} 3 \mathrm{~N} 2$ ou $\mathrm{H} 1 \mathrm{~N} 1$ [23], tout en résistant in vitro aux effets antiviraux du TNF- $\alpha$ et des INF- $\alpha$ et $\beta$ [24].

Mais, alors que le virus H5N1 paraissait ne pas avoir un grand avenir épidémiologique chez l'homme depuis 1997, de nouvelles épizooties sont survenues dans des élevages de poulets et d'autres volailles de Hong-Kong en mai 2001, puis en février et en avril 2002, entraînant de nouveaux pogromes de ces animaux. En février 2003, des cas ont été confirmés chez des résidents de Hong-Kong [25]. Ils avaient voyagé dans la province de Fujian, dans le sud-est de la Chine, les souches virales isolées de ces derniers malades étaient de type aviaire, mais différaient génétiquement de celles isolées en 1997 [25].

Enfin en janvier 2004, H5N1 a réémergé chez l'homme au Vietnam, au Cambodge, au Laos et en Thaillande, tandis que des élevages de poulets et de canards étaient infectés dans ces mêmes pays et en Corée du sud, en Chine, au Pakistan et au Japon. Et le massacre de la volaille a repris de plus belle... Un faucon pèlerin (Falco peregrinus) a même été trouvé mort à Hong-Kong, infecté par H5N1. On redoute toujours, à l'occasion de ces réémergences multiples, un réassortiment génétique désastreux pour notre espèce. D'autant plus que la diversité génétique des souches de H5N1 circulant dans la région semble avoir beaucoup augmenté depuis 2001. C'est peut-être la conséquence des vaccinations réalisées dans les élevages de poulets, en Chine, avec un vaccin insuffisamment immunogène. Il aurait pu masquer la symptomatologie chez les poulets infectés, sans empêcher que ceux-ci diffusent l'infection autour d'eux (NewScientist, 11 février 2004). Pour le moment, il n'existe aucun vaccin à usage humain contre H5N1.

\subsection{L'encéphalite à virus Nipah}

Ce virus a émergé brusquement en Malaisie, en 1998, provoquant une grave épidémie d'encéphalite chez des éleveurs de porcs [26]. Les États de Negri Sembilan, Pérak et Sélangor ont été les plus touchés : 245 cas humains ont été enregistrés entre septembre 1998 et avril 1999, entraînant la mort de 104 malades, soit 39,2 \% [27]. C'était le prolongement humain d'une épizootie porcine qui avait tué $5 \%$ des porcs atteints. On crut d'abord avoir affaire à une poussée d'encéphalite japonaise, mais les données épidémiologiques n'étaient pas en faveur d'une telle hypothèse, même s'il y eut probablement des infections mixtes. En fait, les malades étaient des hommes adultes, souvent vaccinés contre l'encéphalite japonaise et ayant eu des contacts professionnels avec des porcs malades [27,28]. En mars 1999, un autre foyer épidémique apparut à Singapour, touchant 11 travailleurs des abattoirs, infectés par des porcs importés de Malaisie ; il n'y eut heureusement qu'un seul décès [27,29]. L'étude anatomopathologique de 32 cas humains a révélé des lésions diffuses de capillarite nécrosante, notamment au niveau de l'encéphale [27,28,30]. Le virus Nipah, grâce à sa protéine $\mathrm{V}$, peut inhiber l'action antivirale des INF- $\alpha$ et $\gamma$, in vitro [31].

Pour la seule Fédération de Malaisie, plus d'un million de porcs furent euthanasiés [28], ce qui a représenté de lourdes pertes économiques pour ce pays, fort exportateur. Deux militaires sur les 1638 engagés dans ce programme contractèrent une encéphalite tandis que six autres étaient infectés de façon inapparente, malgré le port de masques, de gants, de lunettes et de bottes [32].

Le virus Nipah est apparenté au virus Hendra isolé précédemment en Australie où il a tué des chevaux et des personnes en contact directe avec ces derniers [33]. Ces virus appartiennent à un genre nouveau, Henipavirus, de la sousfamille des Paramyxovirinae. Comme le virus Hendra est associé à des chauves-souris on a, naturellement, recherché des traces d'activité du virus Nipah chez les chiroptères du Sud-est asiatique. Effectivement, des anticorps neutralisant ce virus ont été décelés chez cinq espèces de chauves-souris de Malaisie, tant frugivores (surtout des roussettes) qu' insectivores [34], et chez des roussettes (Pteropus lylei) proposées à la consommation dans des restaurants, au Cambodge [35]. Finalement, le virus Nipah a été isolé des urines de la roussette Pteropus hypomelanus, en Malaisie [36]. Ces chiroptères sont donc, très vraisemblablement les réservoirs du virus Nipah dans la nature.

Depuis l'extermination des porcs infectés, on a plus signalé de cas d'encéphalite à virus Nipah, mais il convient de rester vigilant car les roussettes et les porcs sont très nombreux dans tout le Sud-est asiatique.

Heureusement, la ribavirine semble pouvoir réduire la mortalité chez l'homme [37] et un vaccin recombinant Pasteur-Mérieux est à l'étude [38].

\subsection{Le SRAS ou syndrome respiratoire aigu sévère (SARS, en anglais)}

C'est la première pandémie du $\mathrm{XXI}^{\mathrm{e}}$ siècle, apparue en Chine méridionale, à la fin de 2002. Elle a démontré à la fois la fragilité de nos systèmes de santé et l'intérêt évident d'une coopération scientifique internationale.

Le 15 mars 2003, l'OMS a lancé une alerte mondiale concernant l'apparition à Hong-Kong, d'une épidémie inquiétante de « pneumonie atypique transmissible », baptisée SRAS peu après. Cette maladie atteignait plus volontiers le personnel des Services d'urgence et des sujets relativement âgés, mais pas exclusivement. L'évolution clinique était progressive et la mortalité se situait entre 3 et $10 \%$. Ce n'était pas non plus de la grippe. 
L'épidémie a ensuite gagné Hanoi, Singapour, Beijing, Bangkok, Toronto et Vancouver, se manifestant dans une trentaine de pays. Quelques cas furent rapportés en Europe, dont sept en France, heureusement non mortels. Le personnel des soins intensifs et les proches parents, ceux qui étaient en contact très étroit avec des malades, étaient les plus atteints. L'incubation durait de 48 heures à sept jours.

En fait, dès la mi-novembre 2002, cette épidémie s'était manifestée en Chine du sud, dans la Province de Guangdong, où elle avait tué plus de 300 personnes, sans que les autorités chinoises informent la communauté internationale. Bien plus, elles retardèrent l'accès de la région aux experts de l'OMS.

L'acmé de l'épidémie fut atteint en mai 2003, le dernier pays touché étant Taiwan. Au début de juillet 2003, l'OMS pouvait annoncer la fin de la pandémie. Le bilan global officiel (OMS, 29 août 2003) était de 8422 cas et 916 décès, soit $18,87 \%$.

Le virus responsable fut rapidement isolé et caractérisé au point de vue biologique et génétique [39]. C'était un coronavirus entièrement nouveau, le SARS-CoV dédié au Docteur Carlo Urbani, le représentant de l'OMS à Hanoï, mort dans les premiers du fait de son dévouement. Ce virus différait complètement des coronavirus que l'on connaissait déjà chez l'homme et les animaux domestiques ou de compagnie [40].

La coopération de 11 laboratoires nationaux de virologie, coordonnés par l'O.M.S., a permis ce résultat spectaculaire qui aurait pu être encore plus rapide si les autorités politiques et sanitaires chinoises avaient preuve d'un peu plus de responsabilité [41]. Ce succès ouvrait la voie à la mise au point de tests diagnostiques fiables, de vaccins, d'antiviraux et à la compréhension de la pathogénie du SRAS.

Contrairement à ce qui a pu être dit, les coronavirus ont une certaine résistance dans le milieu extérieur, en particuliers ceux qui infectent les porcs [42]. Cela pourrait expliquer la facilité avec laquelle le SRAS a diffusé, à partir d'un seul cas-index, dans le «Amoy Gardens apartment block » de Hong-Kong, infectant 311 résidents. Chez les malades (comme chez les animaux), le virus est présent non seulement dans les sécrétions nasales et pharyngées, mais également dans les selles (97\% par RT-PCR), et $73 \%$ des patients sont diarrhéiques [43]. D'ailleurs, comment expliquer autrement que par une certaine résistance des virus, les infections de laboratoire rapportées fin 2003 à Singapour et à Taiwan. On a aussi suspecté les rats domestiques d'avoir propagé le SRAS dans le « Amoy Gardens » [44].

Reste l'épineuse, mais essentielle question de l'origine du virus. L'hypothèse la plus vraisemblable est celle d'un réservoir de virus animal. L'attention des virologistes de HongKong s'est rapidement portée sur la faune sauvage ou semisauvage, proposée à la vente sur les marchés du sud de la Chine, afin de satisfaire les goûts culinaires des gastronomes locaux. On y trouve des pangolins, civettes, blaireaux, chauves-souris, singes, serpents, etc., dans une extraordinaire promiscuité avec l'homme. Sur le marché de Shenzhen, dans la Province de Guangdong qui fut l'épicentre de l'épidémie de 2002, ils ont isolé [45] un coronavirus très proche de celui du SRAS chez plusieurs civettes de l'Himalaya (Paguna larvata) et chez un chien viverrin (Nyctereutes trocyonoides). Au même endroit, un blaireau chinois (Melogale moschata) fut trouvé porteur d'anticorps spécifiques.

Les souches virales isolées de ces animaux diffèrent de celles de l'homme atteint de SRAS par la présence, dans leur génome, de 29 nucléotides supplémentaires [45]. Ce n'est probablement pas la consommation de leur viande qui assure la contamination humaine, car ces virus ne résistent pas à la cuisson. Ce serait plutôt le stockage en cage, la vente, le dépeçage et la préparation en cuisine qui permettrait au virus de franchir la «barrière » de notre espèce.

Alors que de nouveaux cas de SRAS sont apparus en Chine, début 2004, de plus en plus d'arguments virologiques et épidémiologiques désignent la civette de l'Himalaya, sinon comme le réservoir primaire du virus, du moins comme le vecteur de l'infection, avec peut-être également les rats [46] et les chats domestiques, ces derniers ayant été trouvés infectés dans le «Amoy Gardens ». Ces conclusions récentes ont valu à plus de 10000 civettes d'élevage un pogrome très médiatisé.

Le SRAS n'a certainement pas fini de faire parler de lui. Des vaccins sont à l'étude. La Ribavirine semble avoir une certaine activité sur le virus.

\section{Discussion et conclusions}

L'étude des émergences virales les plus récentes et les plus graves en Asie, H5N1, Nipah et le SRAS, permet de dégager un certain nombre d'enseignements.

Tout d'abord, la notion de barrière d'espèce parait totalement dépassée. Le virus grippal H5N1 est passé directement du poulet à l'homme, en 1997 et en 2004, sans intermédiaire animal ni réassortiment génétique. On comprend l'inquiétude officielle de l'OMS face à d'éventuelles recombinaisons avec des virus grippaux humains et l'alerte globale lancée le 27 janvier 2004. Le virus Nipah, échappé de chauves-souris, a dévasté des élevages de porcs avant d'infecter l'homme. Quant au coronavirus du SRAS, les enquêtes virologiques réalisées en Chine ont montré que ce virus ou des virus voisins infectent couramment une véritable « arche de Noé » à finalité culinaire (civette, chien viverrin, blaireau). Face à l'émergence de nouvelles zoonoses virales, la notion de « barrière d'espèce » peut même s'avérer dangereuse, en conduisant les autorités sanitaires à sous-estimer les risques pour l'homme d'une maladie animale quelle qu'en soit la nature. On a encore en tête, l'émergence chez l'homme, en 1996, du nouveau variant de la maladie de Creutzfelt-Jakob, dont une soit disant barrière devait nous protéger.

Ensuite, il est de plus en plus évident que la Chine et le sud-est asiatique représentent une formidable machine à faire émerger des virus dangereux pour notre espèce.

Par ailleurs, si l'on cherche à comprendre pourquoi les émergences virales récentes en Asie ont eu des succès émer- 
gentiels variables, il faut faire appel à la biologie moléculaire des virus à ARN. En 1997, à Hong-Kong, L'épidémie de grippe H5N1 s'est arrêtée après que les poulets responsables aient été tous exterminés. Il n'y a pas eu d'extension interhumaine de la maladie car H5N1 n'a pas eu le temps ou l'opportunité, de se réassortir avec des souches du virus grippal A humaines. Toutefois, il faut rester vigilant. Les réémergences récentes de $\mathrm{H} 5 \mathrm{~N} 1$ au Vietnam, en Corée du sud, au Cambodge, en Chine, au Japon et en Indonésie risquent d'apporter à ce virus de nouvelles occasions de réassortiment génétique, d'où l'inquiétude justifiée de l'OMS.

Le coronavirus du SRAS apparaît, à priori, le plus dangereux. Il a bien réussi sa première émergence [40], infectant plus de 8000 personnes, dans une trentaine de pays différents. Il se transmet très bien d'un malade à son entourage immédiat, médical ou familial. Si on applique au SRAS le concept du $R o$ ( «basis reproductive number »), c'est à dire la capacité moyenne à se transmettre, d'un individu infecté à un ou plusieurs sujets réceptifs d'une population non immune [47,48], le SRAS bénéficie d'un Ro nettement supérieur à un, du moins au cours de certaines étapes de sa propagation planétaire. Par comparaison, les infections à H5N1 ou Nipah sont caractérisés par un $R o$ voisin de zéro.

Enfin, si l'on cherche à estimer le poids des facteurs humains et des facteurs environnementaux tels que le réchauffement planétaire, dans le succès émergentiel de ces virus, il est clair que le principal responsable est l'homme lui-même. C'est lui qui a installé des élevages industriels, parfois monstrueux, de volailles (Chine : 1,3 milliard de poulets pour la seule Province de Guangdong), de porcs (Malaisie) ou de civettes (Chine du sud), constituant autant de milieux artificiels favorables à l'éclosion d'épizooties. La mauvaise foi des autorités chinoises face aux problèmes du SRAS ou de H5N1, relève de la nature humaine. En revanche, les changements climatiques, le phénomène El Niño [49], dont la réalité ne peut être niée, représentent pour les virus examinés ici, peu de chose face aux comportements humains et aux habitudes culturelles, notamment alimentaires. Les maladies virales, susceptibles d'être influencées par le réchauffement planétaire sont des infections à transmission vectorielle, faisant intervenir des tiques, des moustiques ou des rongeurs [50]. Ce n'est le cas ni pour la grippe aviaire H5N1, ni pour l'encéphalite à virus Nipah, ni pour le SRAS. Les infections virales dont l'épidémiologie pourrait être modifiée par des changements climatiques, dans le Sudest asiatique, sont plutôt l'encéphalite japonaise et la dengue, mais pour le moment rien n'a été publié dans ce sens.

\section{Références}

[1] Chastel C. Émergences virales chez l'homme et réussite émergentielle. Virologie 2000;4:273-9.

[2] Lee H, Lee P, Johnson K. Isolation of the etiologic agent of Korean hemorrhagic fever. J Infect Dis 1978;137:298-308.
[3] Halstead S. Mosquito-borne hemorrhagic fevers of South and SouthEast Asia. Bull OMS 1966;35:3-15.

[4] Chastel C. Réflexions sur deux viroses d'actualité: la fièvre jaune et la dengue. Ann Biol Clin 1997;55:415-24 (Paris).

[5] Halstead S. Pathogenesis of dengue : challenges to molecular biology. Science 1988;239:476-81.

[6] Chastel C, Camicas J. Arbovirus transmis par des tiques et pathogènes pour l'homme ou pour les animaux domestiques. Bull Soc Entomol Fr 1984;89:775-94.

[7] Shortridge K. Pandemic influenza: a zoonosis. Sem Resp Infect 1992; 7:11-25.

[8] Chomel J, Aymard M. Les virus responsables de conjonctivites hémorragiques. Lyon Med 1975;233:117-28.

[9] ONU/OMS. Le point sur l'épidémie de sida. Genève: Onusida; 2003. p. 14-22.

[10] Beasley R, Hwang L, Lin C, Chien C. Hepatocellular carcinoma and hepatitis B virus: a prospective study of 22707 men in Taiwan. Lancet 1981;2:1129-33.

[11] Nousbaum J. Les sous-types génomiques du virus de l'hépatite C : épidémiologie, diagnostic et conséquences cliniques. Bull Soc Path Exot 1998;91:29-33.

[12] Grandalam M, Nicaud E, Van Cuyek-Gandé H, Buisson Y. Répartition géographique des génotypes du virus de l'hépatite E. Bull Soc Path Exot 1999; 274-7.

[13] Khuroo M, Skidmore S, Sofi M, Khuroo M. Incidence and severity of viral hepatitis in pregnancy. Am J Med 1981;70:252-5.

[14] Snacken R, Kendal A, Haaheim L, Wood J. The next influenza pandemic: lessons from Hong-Kong, 1997. Emerg Infect Dis 1999;5: 195-203.

[15] Zaki A. Isolation of a flavivirus related to the tick-borne encephalitis complex from cases in Saudi Arabia. Tr Roy Soc Trop Med Hyg 1997;91:179-81.

[16] Charrel R, De Lamballerie X. Le virus Alkhurma (famille des Flaviviridae, genre Flavivirus) : un pathogène émergent responsable de fièvres hémorragiques au Moyen-Orient. Med Trop 2003;63:296-9.

[17] De Jong J, Claas E, Osterhaus A, Webster R, Lim W. A pandemic warning. Nature 1997;389:554.

[18] Van Der Werf S. Grippe aviaire A (H5N1) : cul-de-sac épidémiologique ou prémices d'une nouvelle pandémie ? Virologie 1998;2:99101.

[19] Claas E, Osterhaus A, Van Beek R, De Jong J, et al. Human influenza A $\mathrm{H} 5 \mathrm{~N} 1$ virus related to a highly pathogenic avian influenza virus. Lancet 1998;351:472-7.

[20] Subbarao K, Klimov A, Katz J, Regnery H, Lim W, Hall H, et al. Characterization of an avian influenza A (H5N1) virus isolated from a child with a fatal respiratory illness. Science 1998;279:393-6.

[21] Shortridge K, Zhou N, Guan Y, Gao P, Ito T, et al. Characterization of avian $\mathrm{H} 5 \mathrm{~N} 1$ influenza viruses from poultry in Hong-Kong. Virology 1998;252:331-42

[22] To K, Chan P, Chan K, Lee W, Lam W, Wong K, et al. Pathology of fatal human infection associated with avian influenza A H5N1 virus. J Med Virol 2001;63:242-6.

[23] Cheung C, Poon L, Lau A, Luk W, Lau Y, Shortridge K, et al. Induction of proinflammatory cytokins in human macrophages by influenza A (H5N1) viruses: a mechanism for unusual severity of human disease? Lancet 2002;360:1831-7.

[24] Seo S, Hoffmann E, Webster R. Lethal H5N1 influenza viruses escape host antiviral cytokin responses. Nature Medicine 2002;8:950-4.

[25] Nicholson K, Wood J, Zambou M. Influenza. Lancet 2003;362:173345.

[26] Chua K, Goh K, Wong K, Kamarulzaman A, Tan P, et al. Fatal encephalitis due to Nipah virus among pig-farmers in Malaysia. Lancet 1999;354:1257-9.

[27] Chua K, Bellini W, Rota P, Harcourt B, Tamin A, et al. Nipah virus: a recently emergent deadly paramyxovirus. Science 2000;288:1432-5.

[28] Bourgeade A. Identification d'un nouvel agent d'encéphalites en Malaisie : le virus Nipah, proche du virus Hendra. Lettre Infect 1999;14: 282 
[29] Paton N, Leo Y, Zak S, Anchus A, Lee K, Ling A, et al. Outbreak of Nipah-virus infection among abattoir workers in Singapore. Lancet 1999;354:1253-6.

[30] Wong K, Shieh W, Kumar S, Noraim K, Abdullah W, Guarner J, et al. Nipah virus infection; pathology and pathogenesis of an emerging paramyxoviral zoonosis. Am J Pathol 2002;161:2153-7.

[31] Rodriguez J, Parisien J, Horwath C. Nipah virus V protein evades alpha and gamma interferon by preventing STAT 1 and STAT 2 activation and nuclear accumulation. J Virol 2002;76:11476-83.

[32] Roslinah A, Mounts A, Parashar U, Sahani M, Lye M, et al. Nipah virus infection among military personnel involved in pig culling during an outbreak of encephalitis in Malaysia 1998-1999. Emerg Infect dis 2001; 759-61.

[33] Murray K, Selleck P, Hooper P, Hyatt A, Gould A, Gleeson L, et al. A morbillivirus that caused fatal disease in horses and humans. Science 1995;268:94-7.

[34] Johara M, Field H, Roshdi A, Morissy C, Van Der Heide B, et al. Nipah virus infection in bats (Order Chiroptera) in Peninsular Malaysia. Emerg Infect Dis 2001;7:439-41.

[35] Olson J, Rupprecht C, Rollin P, An U, Niezgoda M, et al. Antibodies to Nipah-like virus in bats (Pteropus lylei), Cambodia. Emerg Infect Dis 2002;8:987-8.

[36] Chua K, Koh C, Hooi P, Wee K, Khong J, Chua B, et al. Isolation of Nipah virus from Malaysian Island flying foxes. Microbes Infect 2002;4:145-51.

[37] Chong H, Kamarulzaman A, Tan C, Goh K, Thayaparan T, Kunjapan S, et al. Treatment of acute Nipah encephalitis with Ribavirin. Ann Neurol 2001;49:810-3.

[38] Guillaume V, Contamin H, Loth P, Georges-Courbot M, et al. Nipah virus: vaccination and passive protection studies in a hamster model. J Virol 2004;78:834-40.
[39] Rota P, Oberste M, Monroe S, Nix W, Campagnoli R, et al. Characterization of a novel coronavirus associated vith severe acute respiratory syndrome. Science 2003;300:1394-9.

[40] Vabret A. Coronavirus : une émergence réussie. Virologie 2003;7: 237-41.

[41] Enserink M. China's missed chance. Science 2003;301:294-6.

[42] Cheng K. Enzymatic and acidic sensivity profiles of selected virulent and attenuated transmissible gastroenteritis viruses of swine. Am J Vet Res 1985;46:632-6.

[43] Peiris J, Chu C, Cheng V, Chan K, Hung I, Poon L, et al. Clinical progression and viral load in a community outbreak of coronavirusassociated SARS pneumonia: a prospective study. Lancet 2003;361: 1767-72.

[44] Ng S. Possible role of an animal vector in the SARS outbreak at Amoy Gardens. Lancet 2003;362:570-2.

[45] Guan Y, Zheng B, He Q, Liu X, Zhuang Z, Cheung C, et al. Isolation and characterization of viruses related to the coronavirus from animals in Southern China. Science 2003;302:276-8.

[46] Martina B, Haagmans B, Kuiken T, Fouchier R, Rimmelzwaan G, et al. SARS virus infection of cats and ferrets. Nature 2003;425:915.

[47] Bull J, Dykhuisen D. Epidemics-in-waiting. Nature 2003;426:60910 .

[48] Antia R, Regoes R, Koella J, Bergstrom C. The role of evolution in the emergence of infections diseases. Nature 2003;426:658-61.

[49] Kowats R, Bouma M, Hajat S, Worrall E, Haines A. El Niño and Health. Lancet 2003;362:1481-9.

[50] Chastel C. Incidence des changements climatiques planétaires sur les arboviroses transmises à l'homme par des moustiques et des tiques. Bull Acad Natl Méd 2002;186:89-101. 